CARNETS DE Carnets de géographes

GÉOGRAPHES.

$3 \mid 2011$

Les géographies des enfants et des jeunes

\title{
Gill Valentine (2004), Public Space and the Culture of Childhood
}

London, Ashgate

Camille Valerion

\section{OpenEdition}

\section{Journals}

Édition électronique

URL : http://journals.openedition.org/cdg/2405

DOI : $10.4000 /$ cdg. 2405

ISSN : 2107-7266

Éditeur

UMR 245 - CESSMA

Référence électronique

Camille Valerion, «Gill Valentine (2004), Public Space and the Culture of Childhood», Carnets de géographes [En ligne], 3 | 2011, mis en ligne le 01 décembre 2011, consulté le 25 septembre 2020 URL : http://journals.openedition.org/cdg/2405 ; DOI : https://doi.org/10.4000/cdg.2405

Ce document a été généré automatiquement le 25 septembre 2020.

\section{(1) () 9}

La revue Carnets de géographes est mise à disposition selon les termes de la Licence Creative Commons Attribution - Pas d'Utilisation Commerciale - Pas de Modification 4.0 International. 


\title{
Gill Valentine (2004), Public Space and the Culture of Childhood
}

\author{
London, Ashgate
}

Camille Valerion

\section{RÉFÉRENCE}

Gill Valentine, Public Space and the Culture of Childhood, 2004, London, Ashgate

1 Même si elles ont encore peu d'écho en France, on a vu fleurir dans les pays anglosaxons de nombreuses recherches affiliées aux Children's Studies depuis le début des années 2000. L'ouvrage de Gill Valentine, Public space and the culture of childhood, publié en 2004, présente l'une d'entre elles. L'auteure y interroge l'imaginaire autour duquel se construit l'encadrement des enfants dans l'espace public: d'un côté, les jeunes enfants risquent en permanence de s'y faire agresser ou enlever et, d'un autre côté, les enfants plus âgés, en raison de leurs pratiques sociales marginales, constituent une menace pour l'ordre moral. Dans l'imaginaire collectif, la présence de l'enfant dans l'espace public est donc avant tout source d'inquiétude. Pour Gill Valentine cette anxiété a conduit à la production de normes adulto-centrées d'accès et d'usage de l'espace public, qui nient la réalité sociale de l'enfance.

2 L'enfance étant comprise comme un stade naturel dans les pays d'Amérique du Nord et d'Europe, l'enfant y est perçu à la fois comme vulnérable aux attaques du monde extérieur, parce que faible et naïf, et comme dangereux, puisqu'il est dominé par ses instincts. Le rôle des adultes est donc de le protéger tout autant que de le contrôler. C'est sur cette dualité que reposent, selon l'auteure, toutes les pratiques d'encadrement qui conduisent aujourd'hui à l'éloigner au maximum de l'espace public. Pourtant, en plaçant la focale non pas sur ce qu'on croit savoir des enfants mais sur ce qu'ils font et pensent réellement, on observe qu'ils disposent en réalité d'une palette de compétences insoupçonnées qui leur permet d'évoluer sereinement dans l'espace public. Finalement, l'auteure plaide pour la prise en compte de ces expériences 
enfantines dans le cadre des politiques d'aménagement de l'espace public, de sorte à pouvoir adapter ce dernier aux besoins réels des enfants et, ce faisant, à leur y refaire une place.

3 L'enquête sur laquelle se fondent ces propos a été réalisée dans la région de Manchester, dans le Nord de l'Angleterre, et s'est intéressée à des familles vivant dans des contextes résidentiels très variés (quartiers urbains, péri-urbains ou ruraux; quartiers populaires, de classes moyennes ou mixtes ; quartiers de logement sociaux ou privés). Le travail de terrain a, quant à lui, consisté en la diffusion d'un questionnaire auquel ont répondu quatre-cents parents, dont soixante-dix ont ensuite accepté de réaliser un entretien approfondi, et en l'organisation de groupes de discussions dans les écoles avec des enfants de huit à onze ans.

C'est au moyen des données recueillies auprès des parents que l'auteure identifie d'abord une "géographie des craintes parentales » (geography of parents' fears) focalisée sur l'espace public et déterminée par une conception naturalisante de l'enfance. Elle rappelle ensuite que, contrairement aux idées reçues, les risques d'agression des enfants y sont statistiquement très faibles mais que cette croyance est entretenue par un discours médiatique et parental alarmiste soutenu par l'idée qu'il vaut mieux prévenir que guérir. De plus, la responsabilité parentale étant de plus en plus pointée du doigt, le risque encouru concerne autant les enfants que les parents. En effet, en cas d'agression, la faute sera reportée sur ces derniers, coupables de n'avoir pas su protéger leur enfant. Ils risquent donc de commettre une faute, qu'ils considèrent euxmêmes comme impardonnable, et d'être catalogués comme mauvais parents par l'ensemble de la société. Toutefois, à chaque espace local correspondent des mesures de protection et des craintes spécifiques puisque les caractéristiques de l'espace public et la figure de l'étranger peuvent varier d'un lieu à l'autre. De cela découle l'existence de ce que l'auteure appelle des « cultures parentales locales » (local parenting cultures).

5 Par ailleurs, ces cultures parentales varient aussi selon le sexe des parents et des enfants et selon les structures familiales. Parce que les pères sont toujours censés être les garants de l'autorité, ils imposent des restrictions plus fortes que les mères à leurs enfants tandis que les garçons, désormais considérés comme irresponsables et immatures, sont plus encadrés qu'auparavant. Dans le cas des familles monoparentales, les restrictions sont moins fortes que pour les familles traditionnelles puisque les parents ont moins de ressources, financières et temporelles, à allouer à la garde des enfants. Ainsi, les normes de gestion du risque (risk management) sont produites à plusieurs niveaux (national, local, familial) tout en ayant le même point de départ : une définition de 1' enfant comme être vulnérable.

6 Pourtant, dans le cadre des groupes de discussion, tous les enfants qui ont déjà eu une expérience malheureuse dans l'espace public ont montré qu'ils étaient capables d'adopter des solutions rationnelles face au danger, contrairement à ce que croient leurs parents. Par conséquent, l'auteure propose de considérer la notion de " compétence », jusqu'ici utilisée uniquement en référence à l'âge de l'enfant, comme un concept performatif. Au lieu de dispositions gagnées avec les années, les compétences seraient en réalité des catégories de pensée de l'autonomie enfantine construites à la croisée des cultures parentales et des performances enfantines. La compétence ne serait donc qu'un mot mobilisé tantôt par les parents pour justifier les restrictions imposées aux enfants, tantôt par les enfants pour justifier un gain d'autonomie au regard de ce qu'ils se sont montrés capables de faire. 
Gill Valentine revient ensuite sur la transformation en cours des espaces publics en espaces «adultisés». En raison des craintes nourries par les parents, elle observe l'augmentation significative des activités extrascolaires, dont la caractéristique principale est de transformer le temps libre de l'enfant en temps encadré. Désormais, le temps qui n'est passé ni à l'école, ni à la maison est de plus en plus mobilisé dans le cadre de ces activités, ce qui entraîne une diminution de l'usage autonome des espaces publics. L'enfant passe ainsi d'un adulte protecteur à un autre, de façon à ce que ses parents sachent toujours où, et avec qui, il se trouve.

Parallèlement, les enfants plus âgés, préadolescents ou adolescents, sont de plus en plus repoussés à la marge de l'espace public avec le développement des espaces à vocation commerciale, comme les centres commerciaux ou les rues marchandes, qui se substituent aux espaces purement publics. Surtout, les terrains vagues, les friches urbaines ou les espaces sans fonction particulière se raréfient tandis que les adolescents ont besoin de trouver des lieux où se réunir et ne rien faire (hanging around). Ils se trouvent donc obligés d'utiliser les mêmes lieux que les adultes, c'est-àdire des lieux fonctionnels dans lesquels leurs activités, qui se résument à ne pas avoir d'activité, semblent marginales. Ils perturbent donc le fonctionnement normal de ces espaces et passent alors pour des êtres menaçants.

En somme, l'espace public semble de moins en moins conçu pour accueillir les pratiques autonomes des enfants de tous âges. À force d'en être éloignés dès leur plus jeune âge, ces derniers n'y trouvent plus leur place et ne peuvent donc pas profiter d'une vie sociale extérieure. L'espace public est donc bien en partie privatisé pour ne plus répondre qu'aux besoins des populations adultes, repoussant à la marge le groupe des enfants qui se définit pourtant par des déplacements de proximité et des ressources en temps libre bien supérieurs à ceux des adultes.

10 En définitive, pour l'auteure, les géographies des enfants sont dépendantes d'un rapport social qui distribue les ressources spatiales de façon inégale entre enfants et adultes, et ce rapport est décisif dans la production de l'espace public. Ainsi, cette recherche s'inscrit dans la lignée des travaux français interrogeant les dimensions spatiales des rapports sociaux (Chamboredon et Lemaire, 1970, Pinçon et PinçonCharlot, 1989, Bourdieu, 1993, Magri, 1993, Retière, 2003) tout en introduisant un objet nouveau: la dimension sociale de l'enfance. L'ouvrage met surtout en évidence l'efficacité d'une telle alliance. En mêlant réflexions sur l'espace et sur l'enfance, l'auteure prouve que ce pan de la recherche en sciences sociales a tout lieu d'être et permet d'ouvrir de nouvelles perspectives dans les deux champs. Toutefois, le propos présenté ici reste introductif puisqu'il ne lie que très peu ce rapport social d'âge avec les autres rapports sociaux et présente les enfants comme faisant partie d'un groupe social homogène. Or, si les cultures parentales peuvent varier, le rapport enfant-adulte n'est pas figé et peut connaître des variations d'un groupe à un autre, ce qui suggère que les pratiques sociales enfantines sont elles aussi variables et donc que, sous le terme d'enfance, sont regroupées différentes réalités sociales. 


\section{BIBLIOGRAPHIE}

BOURDIEU P. (1993), « L'effet de lieu », in BOURDIEU P. (dir.), La misère du monde, Paris, Seuil.

CHAMBOREDON J.-C. et LEMAIRE M. (1970), « Proximité spatiale et distance sociale. Les grands ensembles et leur peuplement. », Revue française de sociologie, vol. XI, n 1, pp. 3-33.

MAGRI S. (1993), «Villes, quartiers : proximités et distances sociales dans l'espace urbain », Genèses, $n^{\circ} 13$, p. 151-165.

PINÇON M et PINÇON-CHARLOT M. (1989), Dans les beaux quartiers, Paris, Seuil.

RETIERE J.-N. (2003), « Autour de l'autochtonie. Réflexions sur la notion de capital social populaire », Politix, n63, pp. 121-143.

INDEX

Thèmes : Carnets de lectures

\section{AUTEURS}

\section{CAMILLE VALERION}

Université Lyon 2

Centre Max Weber

Sociologie

camil1e-va1erion[at]club-internet.fr 